\title{
An Analysis of Overweighed Higher Education Cost in Impoverished Countryside Families
}

\author{
Guoqiang Tang \& Xian Zhan \\ College of Management, Tianjin Polytechnic University \\ Tianjin 300387, China \\ E-mail: zhangxian842003@yahoo.com.cn
}

\begin{abstract}
In 1997, China's general universities carried on the "the axle" policy on tuition charging, and then the tuition of general higher education increases rapidly. Students' education charges keep increasing and occupy a large proportion of people's household income. The excessive burden undertook by private families, especially impoverished countryside families has beyond their capacity. The soaring tuition of higher education will directly lead to the poverty of rights and opportunities of education in poor families and will result in disparity in education. This paper delves into researching the current situation of poor families' investment of higher education, analyzing the problem of overweighed higher education cost and its fundamental causes. Then try my best to put forward some suggestions.
\end{abstract}

Keywords: Countryside, Impoverished families, Higher education cost

\section{The concept of the educational cost}

"Educational cost" was proposed by the western economists who tried to apply the economic cost to the education, and it was also proposed with in-depth study of economics. Educational cost was originated from the western theory of human capital cost which was established by Schultz (1990, p.2), a modern American famous economist. He thought that education investment is a kind of human capital investment, and "schools can be regarded as specialized factories producing degree; educational institutions (including various schools) can be regarded as industrial sectors". Thus, like the factories and industrial sectors, schools and educational institutions also should attach importance to educational expenses, because "cost is the basic problem in economics of education research". Educational cost is the basic problem in the development of education.

Wang Shang-mai (1999, p.5), a Chinese scholar, think that "educational cost is the value of consumed educational resources in cultivating students, in other words, all the expenses are paid directly or indirectly by society, educated individuals and families for education in the form of monetary".

Fan Xian-zuo (1999, p.2) considers that "educational cost is social labor cost in the progress of culturing students, including materialized labor and living labor. The monetary expression is all the expenses are paid directly and indirectly by society and educated individuals in educating".

Higher educational cost considered in this paper mainly refers to the completely educational expenses paid by educated students' families.

In the 1970s, John stone, an American economist, put forward a theory of cost sharing in higher education. From his view, in any social, system, or countries governments, parents and students, taxpayers and higher colleges must share the cost of higher education.

Since 1980s, the pattern of cost sharing in higher education has altered worldwide. In order to meet the expansion funds need of expending scale of higher education and gradually improving level of average spending, many countries have taken began to collect partial educational cost from educates or raise the level of training cost to make up for funding deficiencies in higher education.

In 1994, China promulgated Implementation Opinions of Outline in Chinese Higher Education Reform and Development. It proposed to implement policy that students in institutions of higher education, secondary specialized schools and technical schools should pay for education. "Payment standard is determined by education department 
according to a certain proportion of average cost of training and ability of society and parents considering the places and schools (or professionals)". Higher Education Law stipulates that educational administration department and other relevant departments in state council provide annual expenditure criteria and basic principles of raising capital in institutions of higher education.

\section{Present situations, problems and adverse effects of higher educational cost in rural poor families}

\subsection{Family burden situation and problems of higher education personnel training in the current countryside}

China is a developing country, and economic underdevelopment, especially for the rural economy. The basic national conditions determine that poverty standard in China current and a longer period will be a low standard. In recent years, the poverty standard is stable, and it is about 600 yuan after 2000. It was 668 yuan in 2004, 683 yuan in 2005 and 693 yuan in 2006. (Zhang \& Zhao, 2008, p.100)

Based on the current poverty standard, income of poor family is less than 3500 yuan, according to the five people per household. However, since 1994, our college tuition rose from several hundred yuan to 5,000 yuan each year. If we add up the cost of living for students, all income of three families at least can afford a student to receive higher education.

According to the survey, the annual net income of poor farmers in Qinghai is below 800 yuan. But in recent years college students in Qinghai spend about 1 million yuan in tuition fees and living expenses each year. A family needs 4 million yuan at least to support an undergraduate. The cost is higher when students study outside the province. It is equivalent to the income of impoverished farmers for 50 years.

An online survey of 19781 in SOHU shows that $76.69 \%$ think that the college tuition is very high now and $19.31 \%$ think relatively high. That is to say $96 \%$ think tuition is not reasonable. From the fact that there are more than half students are come rural areas, this finding should not be surprising.

Expensive cost of higher education not only make the ordinary families live in dilemma, but also it make poverty families overwhelmed.

\subsection{Adverse effects of higher education overweight in rural poor families}

2.2.1 Education loses its core purposes. Higher education is to provide the community outstanding talents, and it pays more attention to recruitment training than basic education. But higher education should not violate the essence of education. If because of poverty rather than individual quality problems caused some groups cannot enjoy the right to education, education will lead to social different in some extent. The core purpose of education should be promoting social integration, narrowing the gap in society and promoting social justice.

2.2.2 Some people's educational rights will be caused impoverished. Educational rights poverty refers to that the constitution and the laws stipulate that citizens have the right to be educated, but because of economic, social and cultural individuals cannot enjoy such right in fact. (Gao, 2005, 164) In other words, citizens have the honorary rights to be educated, rather than the real rights. Students cannot get higher education, quasi-public goods provided by the government and market, because they cannot afford the necessary educational expenditure. Thus, the educational rights poverty is resulted. Higher educational rights poverty will directly cause the unfair educational opportunities, which mainly refer to a person who reaches the entrance requirements and has to give up the higher educational opportunity because of income, gender, class, and geographical position.

2.2.3 There are negative effects to elementary education in poor areas. Currently the phenomenon that young children lose opportunity to attend school and discontinue their studying is very common in countryside. Except for unreasonable charge in primary and middle schools, an important reason is more and more families lose confidence to the future for students. Even though a child can pass the college entrance examination, they cannot afford the tuition fee, which may take a few years of their savings. Higher tuition of higher education not only has a negative effect on higher education itself, but also it has a negative impact on rural junior secondary education. The proportion of students in institutions of higher education from villages drops further. So far, the rate of higher educational in countryside has been far below the cities.

Overweighed higher education cost in impoverished countryside families has many troubles. Therefore, it is necessary to study the causes to take corresponding countermeasures.

\section{The reasons of overweighed higher education cost in impoverished countryside families}

\subsection{Charge high fees for higher education}

Interim Measures of Administration in Higher Educational Charge in 1996 stipulates that the proportion and standard of tuition in annual average culture cost is decided together by State Board of Education, State Development Planning Commission and Ministry of Finance. At present, the proportion of tuition in annual average culture cost should not more than $25 \%$, and the specific ratio must be adjusted on economic development and the masses ability. 
From the overall cost of higher education, China Statistical Yearbook of Educational Expenditure (2002) shows that higher educational tuition in 2001 is 31.243 billion yuan, accounting for higher educational income $25.75 \%$. It has already surpassed the highest proportion, and the principle of the decision is only on paper.

From the single student, according to the daily operation cost, culture expenditure for average science student is about 1.5 million yuan per year, and arts student is about 1.2 million to 1.3 million yuan per year. If in requirement "no more than $25 \%$, science student should pay for a maximum of 3750 yuan, and arts student should pay about 3000 yuan." But nowadays in general schools fees are between 4000 and 5000 per year, and some of the art majors are more than 8000 yuan.

\subsection{Government expenditure on higher education is still far from the intended target}

In 1993, Central Committee and State Council promulgated the Outline for Chinese Education Reform and Development, which propose the target that "gradually improve the proportion of state financial education expenditure in GDP will reach 4\% at the end of the century. At that time, $4 \%$ was the average level in developing countries, not a higher standard. However, since then the proportion of government's financial investment in education has actually fallen, and is wandering in the lowest level. From 1999 to 2007, the proportion was around 3\%. In 2006, the proportion is $3.01 \%$, and is $3.32 \%$ in 2007 . This is equivalent to the least developed countries.

\subsection{Government doe is not take enough policies to support poor students}

Government is the core strength to determine the higher education development. This is not only because the government's investment in determines the higher education development, but also the government's policies affect the prosperity and weak of higher education. The government's policies supporting impoverished students involved in many aspects. Here we talk about from two aspects that are government attracts funding for higher education and takes "Green Channel" for impoverished students.

We do not have perfect taxation system to attract higher education donation from companies and individuals. Developing countries and developed countries are both paying attention to the support from society for higher education. In western countries, government investment accounts only half around, but there is considerable income from donation and selling service from institutions of higher education. China is ongoing reform of the political system of "small government, big society", and the fundamental aim is transforming the government function. The social main body returned to society, and the government is responsible for the items which society cannot undertake or unwilling to undertake. This requires that government make perfect policies to encourage companies and individuals to support higher education, and expand the financing channels for higher education.

"Green Channel" we taking now for poor students are not comprehensive enough to resolve loaning to school. Government has not constructed college credit system, and students do not have perfect individual system. The risk of bank loans cannot be reduced, and banks will not accede to the demands of student loans. Therefore, improvised students cannot be entered the scope of loans.

\section{The methods of relieve the overweighed higher education cost in impoverished countryside families}

\subsection{Strict control charging of higher education}

Educational cost is the main basis for tuition. According to the theory of higher education cost sharing, higher educational cost is the primary basis for higher educational tuition. The educational cost here is supply side of higher educational service - the cost of cultivating students in institutions of higher education. It does not include individual educational cost paid by student (or family), or indirect educational cost (opportunity cost) by society and students.

4.1.1 The expansion of institutions of higher education has made more than 1.5 thousand public universities owing 2 to 2.5 hundreds million, not including engineering owing and funds gather in schools. In the progress of expansion, the waste at last will be counted in higher educational cost, and will be burden by government finances and students. (Tong, 2007) This is the most important reason why higher education cost cannot decline. We should make policy to control the hardware investment of institutions of higher education. Therefore, higher educational cost of culturing students can be reduced, and students can reduce the burden.

4.1.2 Higher educational tuition should consider the inhabitant income. Education is the development needs rose from satisfaction of living needs, and educational expenditure is part of people's total expenditure. The ability for paying tuition depends on the structure and level of expenses and ultimately it depends on the level of people's income. "According to the statistics which from 33 countries of Word Bank, the proportion of tuition is about $10 \%$ of 20 countries in public institutions of higher education funds, and $20 \%$ of 10 countries. The average of the proportion is $13 \%$ to $15 \%$, and the highest is Korea which the proportion reaches $40 \%$." (Tong, 2007) In both developed countries and developing countries, higher educational cost should be burden by the governments. Particularly in developing countries, the proportion of fees should be lower, because the per capita GNP is low. 
4.1.3 Because education has a special position in economic and social development, people pay more caring than on general interests. The determination of higher education fees should give public enough participation. The government holds hearing for higher educational fees that will help improve the scientific and transparent of charging. It will in favor of agreement with charges in parents and society, and also help improve community supervision.

\subsection{Strengthen the government's funding in higher education}

In the future higher educational fees should improve the main channel of government funding. This reflects the funds put into public universities by government should be improved as soon as possible, so that the proportion will achieve the basic goal that the proportion of GDP 4\%. Then develop higher education in a further step. Because the main channel is government funding, the government can ensure the direction of running schools and imply educational policies by controlling investment in higher education. Eventually that education for the fundamental interests of the people will be realized.

4.2.1 Reforming the government appropriation system and mode to improve the benefit of government appropriation. The government capacity of finance income and budget should be enhanced, and non-budgetary expenditures should be reduced gradually. The assessment of input and output efficiency should be an important indicator of financial appropriation, and paying full attention to the use of assessing the incentive mechanism. Government should narrow the investment imbalance between institutions of higher education, and government increases investment through building jointly in the local government and the central educational department. The central government investment should incline to universities in the west, minorities and places which has inadequate conditions for running institutions of higher education. Various types of universities should take part in local economic construction and social development actively, and government ought to create favorable conditions for it.

4.2.2 Reforming college financial system and strengthening the cost accounting to avoid waste and inefficient. Colleges and universities should strength democracy construction of economic operations and cost management. It should imply annual report system by president that includes school operation and financial situation, so that it could meet the teachers and students right to know and accept the democratic supervision and appraisal of quality and effectiveness from society, teachers, and students.

\subsection{Advocates the funds support to higher education from community}

The problem of higher educational input cannot be separated from social concern and support, so higher education should consistent with the needs of the community. Talents cultivated in colleges and universities should meet the requirements of economic and social development, so the input also needs the support from individuals, enterprises and charity.

With the deepening of reform and opening-up and the policy guidance that some people get rich first, China has formed a rich class. We should pay full attention to social effects of this class, formulate relevant laws, regulations and tax policies. Formation public opinion in a positive atmosphere to promote rich class joins in social welfare, especially higher education actively.

In the west, the social donation plays an important role to the vigorous development of higher education. As in the United State, American universities got 26.5 billion dollars donations in 2005 at least, growth $4.9 \%$ over the previous year. Stanford University got 603.6 million dollars donations, the top in schools. University of Wisconsin won the amount of donations in the second that was 595.2 million dollars. The following are Harvard University (589.9 million dollars donations), University of Pennsylvania (494.3 million dollars donations) and Cornell University (353.9 million dollars donations). (Cai, 2006)

China is a socialist country, and the ultimate aim of social development is common prosperity. We not only have the correct direction, but also have excellent traditional virtues, such as "in obscurity, scholars would maintain their own integrity. In times of success, they would make perfect the whole empire". In recent years, some universities have set up special agencies to raise funds, and social input has increased year by year. A survey that was taken in 30 institutions of higher education belonged to Ministry of Education shows that 8 universities have set up the foundation and 6 universities are ready to set up. At the end of 2003, the total income of Tsinghua University through foundation reaches 807 million yuan; Peking University Education Foundation got 650 million yuan donation from 1998 to 2000. By the end of 2005, the council of Nanjing University donates more than 130 million yuan in the 8 years. (Cai, 2006)

To sum up, the development of higher education plays important roles in cultivating human capital and improving citizens' qualities. In the face of the problem that overweighed higher education cost in impoverished countryside families, we should take all kinds of methods to resolve it. To develop higher education and cultivate high quality talents are the basic engineering construction of implementing the strategy of revitalizing China through science and education and building an innovative country. 


\section{References}

$86.1 \%$ people think university tuition fees too high. (2007). [Online] Available: http://edu.people.com.cn/GB/1053/5282015.html (April 6, 2008).

Cai, Ke-yong. (2006) Social donation: gold mining of higher educational expedition that is in urgent need of excavation. China education newspaper, 26 October 2006.

Campus view: Charge in Chinese universities is three time more than the highest in the world. (2005). [Online] Available: http://news3.xinhuanet.com/school/2005-07/19/content_3231913.htm (April 6, 2008).

Education return the poverty_-graduates' once employment is only 46\% in Qinghai. (2006). [Online] Available: http://www.eol.cn/20060811/3203218.shtml (April 6, 2008).

Fan, Xian-zuo. (1999). Education economics. Beijing: People's Education Press.

Gao, Shu-guo. (2005). Analysis of rural education policies of China. Analysis of public policies of China. Beijing: Social Sciences in China Publishing House.

Theodore. W. Schultz. (1990). Investment in Human Capital. Beijing: Beijing Economic College Press.

Tong, Da-huan. (2007). Educational cost cannot be accounted because of no democratic decision-making. [Online] Available: http://guancha.gmw.cn/show.aspx?id=2937.

Wang, Shang-mai. (1999). Research on educational inputs and outputs. Shijiazhuang: Hebei Education Publishing House.

Zhang, Hong-sheng, \& Zhao, Yu. (2008). Review standard of China's rural poverty. Shanxi: Theoretical exploration, 98-100, 126 